\section{Trabalho e sofrimento em gestores de uma empresa pública em reestruturação}

\author{
Work and distress among managers \\ in a state-owned company undergoing \\ a restructuring process
}

Luiz Carlos Brant 1

Elizabeth Costa Dias 2

\section{Introdução}

A cross-sectional study conducted in a stateowned company undergoing a restructuring process in Greater Metropolitan Belo Horizonte, Brazil, aimed to identify manifestations of distress among managers. The study used the SelfReport Questionnaire-20 (SRQ-20), a socioeconomic questionnaire, document analysis, and a focus group. The principal manifestations of distress were: anxiety (73.2\%); sadness (43.7\%); and dissatisfaction (39.0\%). Of the nine study variables, only gender was statistically associated with distress $(p<0.05)$. Females showed significantly greater distress than males $(O R=6.0$; 95\% CI). The focus group was an important instrument for identifying distress, while the questionnaires helped identify defensive strategies, despite the conceptual differences that were observed. The conclusion was that the utilization of distinct methodological approaches in studies on distress can lead to findings that help produce and develop the field of Workers' Health.

Psychological Stress; Mental Health; Occupational Health
Se o sofrimento constitui uma das expressões fenomênicas da insistência do homem em viver em um ambiente que lhe parece adverso, se o trabalho permite a construção do sujeito como ser de cultura e é fator primordial de sua manutenção, torna-se importante compreender a relação desse sujeito com o sofrimento e a circunstância em que o próprio trabalho, no papel de elemento de transformação, revela-se uma ameaça.

Talvez para muitos, o trabalho pós-industrial possa parecer mais humano quando comparado àquele do século XIX e meados do século XX, que vai do chão de fábricas insalubres e aglomerações humanas nos centros urbanos europeus até as monótonas linhas de montagens. Porém, não se pode esquecer que o trabalho contemporâneo, marcado pelos contratos temporários, pela flexibilização e execução de projeto, em que cada um deve tornar-se responsável pela sua empregabilidade, pode tanto oferecer condições para o crescimento pessoal, como constituir-se em uma nova fonte de opressão, exploração ou exclusão. Ao longo desses dois séculos, ocorreram conquistas e retrocessos. No que se refere ao processo de trabalho, houve uma maior participação dos trabalhadores; as condições de vida e de trabalho melhoram, transformando particularmente os níveis de desgaste físico e os riscos de aciden- 
tes. Observam-se também mudanças nos padrões de exploração. Na atualidade, a capacidade de pensar, criar e tomar decisões passou a ser mais explorada. Qualquer que seja a direção, o trabalho parece constituir-se numa fonte de sofrimento.

Ao buscar, na literatura especializada, subsídios para compreender a relação entre sofrimento e trabalho, foi possível encontrar um grande número de estudos contemplando trabalho e subjetividade, tais como Uchida 1 , que pesquisou a temporalidade e subjetividade, e Lopes 2, que analisou o trabalho, a saúde e a cidadania. De forma semelhante, é ampla a literatura sobre o trabalho e sofrimento psíquico, como se pode constatar em Merlo ${ }^{3}$, que investigou o prazer e sofrimento no trabalho, e em Palácios 4, que estudou o trabalho de caixa bancário. No entanto, até onde foi possível pesquisar, pouco se tem enfocado a subjetividade diferenciada de individualidade na saúde do trabalhador 5 .

A opção por pesquisar o sofrimento em uma população de gestores está relacionada à hipótese de que esses profissionais, na qualidade de sujeitos divididos entre a obediência e resistência às demandas organizacionais, parecem encarnar, estrategicamente, as "proibições" de manifestação do sofrimento, reproduzindo assim a atual cultura do individualismo na gestão do trabalho. Todavia, esse movimento não se faz sem a resistência de alguns atores sociais envolvidos, situação que reforçou o desejo de compreender como se articulam as dimensões do sofrimento e trabalho, da produção e reprodução de determinadas ideologias.

Investigar uma situação, no momento exato de seu acontecimento, no interior de uma empresa, constituiu uma oportunidade rara que só foi possível em virtude de uma conjunção de forças institucionais. O objetivo era evidenciar as manifestações do sofrimento em gestores, durante um processo de reestruturação organizacional, e conhecer algumas de suas percepções, idéias e imagens acerca desses sofrimentos.

\section{Sujeito, trabalho e sofrimento}

Os seres humanos não nascem sujeitos, tornam-se tanto subjectus (produto), quanto produtores de processos sociais através do trabalho. Na relação homem-trabalho-sujeito, o trabalho ocupa uma posição em que a possibili- dade do reconhecimento joga com a morte e criação. A mediação destrutividade/construção entre o homem (ser da natureza) e o sujeito (ser da cultura) se faz pelo trabalho que pode tornar-se razão de viver e morrer. O sujeito em Gramsci 6 é entendido não como sujeito individual, mas resultado de um processo histórico de relações sociais concretas. $\mathrm{O}$ trabalho está no centro do processo de humanização do homem, configurando-se, portanto, como referencial fundante da práxis social. O homem adquire, com o desenvolvimento do trabalho, a diferenciação em relação ao mundo natural, e é essa distinção que o direciona para o simbólico.

O trabalho constitui-se como espaço de dominação e submissão do trabalhador pelo capital, mas, igualmente, de resistência, constituição e do fazer histórico dos trabalhadores num processo lento, contraditório e desigual 7. Assim, dominação, submissão e resistência comportam uma conjunção de forças, na qual o conflito é o elemento central. Falar em conflito é falar em embate, portanto, em sofrimento. A expressão "lento, contraditório e desigual” remete à imagem de uma falta que abre possibilidade para a instauração de uma diferença que se arrasta por uma temporalidade igualmente faltosa.

A transformação, que vai da "coisa” que nasce ao homem que trabalha, é atravessada pelo sofrimento, expressão de um embate entre preservação e destruição das consciências, segundo a concepção de Hegel 8 . Ao mesmo tempo em que o sujeito se submete a uma outra consciência para ser reconhecido em sua individualidade, ele precisa romper com este "outro" para que possa afirmar-se como sujeito único, diferenciado, e assim dar entrada no mundo simbólico. Para isso, uma das formas que o sujeito encontra é levar até o senhor o produto de seu trabalho, o mundo transformado em objeto de satisfação do desejo do senhor. A passagem do homem do mundo da natureza à ordem da cultura se faz a partir de um corte que deixa vestígios mesclados de prazer e sofrimento na memória e no corpo. Não há trabalho sem dor nem sem esperança, assim como não há lembranças sem sofrimento, sem o desejo do eterno retorno ao paraíso perdido.

Para Freud ${ }^{9} \mathrm{o}$ sofrimento está relacionado com o perigo. A ansiedade (angst) descreve um estado particular de esperar ou prepararse para o perigo, ainda que possa ser desconhecido. O medo (furcht) exige um objeto definido de que se tenha temor (fürchtet). O sus- 
to ocorre quando o sujeito se defronta com um perigo sem estar preparado para enfrentálo. O ponto central dessa definição é tanto o perigo, quanto a expectativa, elementos que podem oferecer significativas contribuições para o estudo do sofrimento em gestores. O sofrimento não constitui um dado da natureza, mas uma posição designada, assumida e reconhecida, culturalmente, entre sujeitos históricos. O sofrimento, além da sua inscrição no corpo, pressupõe a existência de uma linguagem que permita identificar algo como perigoso ou não, estranho ou familiar. Logo, consideramos o sofrimento como contingente ao ato de viver. Ele se configura como uma reação, uma manifestação da insistência em viver sob circunstâncias que, na maioria das vezes, não é favorável ao homem. Consideramos também inadequado falar em sofrimento psíquico, como tem sido utilizado, com certa freqüência, em alguns estudos. A utilização do adjetivo psíquico permitiria supor a existência de outros tipos de sofrimento. Qualificar o sofrimento abriria possibilidades de fragmentá-lo em físico, moral, espiritual, entre outros, de acordo com a ideologia e o limite do olhar de cada um. Psique, assim como mente, é "algo misterioso, incapaz de ser descrito nos mesmos termos que nós descrevemos mesas, árvore e átomos" 10 (p. 16).

\section{Métodos}

Optou-se por um estudo transversal com utilização de abordagens metodológicas quantitativas e qualitativas. Foram convidados para participar da pesquisa 132 gestores, totalidade do quadro gerencial, no período de janeiro de 1995 a janeiro de 2000. Todos pertenciam a uma empresa pública, do setor de serviços, que se encontrava em processo de reestruturação tecnológica e organizacional, situada na região metropolitana de Belo Horizonte, Minas Gerais, Brasil.

Utilizou-se a análise documental como uma técnica de investigação, segundo a concepção de Bardin 11, com o objetivo de evidenciar a situação do gerente durante o processo de reestruturação. Foram solicitados à empresa os boletins informativos publicados entre $1995 \mathrm{e}$ 2000 e empregou-se o Self-Report Questionnaire-20 (SRQ-20), um screening validado por experimentação em populações brasileiras por Mari \& Williams 12. Quanto ao questionário sócio-econômico, este foi formatado com perguntas que possibilitassem a composição das características sócio-demográficas.
As variáveis do estudo foram dicotomizadas: (1) variável dependente - sofrimento (ausência e presença); (2) variáveis independentes - tempo de empresa, tempo de gerência, idade, gênero, situação conjugal, turno de trabalho, propriedade da casa, salário e cargo. Todos os resultados foram considerados significativos para uma probabilidade de significância inferior a $5 \%(p<0,05)$, havendo, por isso, pelo menos 95\% de confiança nas conclusões apresentadas.

Grupo focal, como técnica de entrevista, foi utilizado conforme a concepção de Krueger 13, e as vinte perguntas do SRQ-20 foram empregadas como roteiro. Os 71 funcionários que responderam o SRQ-20 foram convidados para participar de uma discussão em grupo, que teve a duração de duas horas. Os 27 participantes do grupo focal, receberam a instrução de atribuir uma nota de 0 a 100 para cada uma das perguntas, segundo a sua percepção acerca do sofrimento, estabelecendo em seguida um debate sobre os diferentes pontos de vista. Definiu-se 0 para ausência de sofrimento e 100 para sua plena existência. Com esse procedimento, pretendeu-se investigar as percepções que os gestores tinham do sofrimento.

Para análise dos dados qualitativos (análise documental e grupo focal), utilizou-se o método análise de conteúdo 11,14,15. Ao analisar o material, buscou-se integrar as estruturas semânticas ou lingüísticas às estruturas sociológicas ou psicológicas a que correspondiam os significados caracterizados pelo contexto organizacional.

O escore dicotômico do SRQ-20 foi definido em sete, seguindo a orientação dos trabalhos realizados por Oliveira 16 e Palácios 17, aqui assumido como estado de sofrimento, constituindo, assim, a variável dependente. As comparações entre os gerentes com e sem sofrimento, quanto às variáveis tempo de empresa, tempo de gerência, salário, renda e idade, foram realizadas utilizando-se o teste $\mathrm{t}$ de Student para amostras independentes, com o objetivo de avaliar diferenças significativas entre os dois grupos (gerentes com ou sem sofrimento). As associações entre os fatores de interesse em relação à presença ou não de sofrimento foram realizadas utilizando-se o teste exato de Fisher que identifica variáveis que possam ser determinantes na ocorrência de um evento (presença ou não de sofrimento). Quando foi constatada uma diferença significativa entre as duas variáveis, avaliou-se a odds ratio (razão das chances), que quantificou o grau de associação entre elas. Um modelo de regressão logística foi ajustado para identificar as variáveis (fatores) que influenciavam a presença ou não 
de sofrimento. O teste de Wald (W2) foi utilizado para verificar, individualmente, se o fator tinha ou não efeito na resposta.

O presente estudo obteve aprovação do Comitê de Ética em Pesquisa da Universidade Federal de Minas Gerais, sob o parecer de no 021/00, aprovado em 16 de março de 2000.

\section{Resultados e discussão}

A análise documental possibilitou contextualizar a reestruturação organizacional e a situação do gestor na empresa investigada. Permitiu observar a posição que as instâncias superiores assumiam nas publicações internas da empresa diante das incertezas e dúvidas sobre o futuro dos seus trabalhadores. Possibilitou ainda identificar algumas das pressões a que os gestores estavam submetidos, oferecendo assim elementos para a compreensão de alguns sofrimentos manifestados no grupo focal e SRQ-20.

Iniciado em 1995, o processo de reestruturação, com vistas à privatização da empresa, considerada por muitos um verdadeiro patrimônio nacional, tornou extremamente atual a afirmação dos jovens Marx \& Engels 18: tudo o que é sólido se evapora no ar. Em meio à sua transformação, anunciava a empresa: "Os desafios do futuro: virar S.A., acelerar sua modernização e vencer as novas disputas do mercado" (Boletim informativo no 9, 2000). Nesse contexto, aquele que ocupava cargo gerencial estava submetido a elevadas exigências. "É preciso buscar o cliente onde ele estiver e criar oportunidades onde, aparentemente, não há o que fazer" (Boletim informativo no 2, 1998). Esse gestor vivia também um conflito entre a esperança de criar, imprimindo algo pessoal ao trabalho, e a incerteza da permanência na função. Esse desejo de colocar uma marca própria no cargo estava, desde a sua origem, condenado a encontrar dificuldades, exigindo grandes esforços. Com a manchete "Necessidade impulsiona novas idéias" o Boletim informativo no 2 do ano de 1998 apresenta as estratégias de um de seus gestores. "Aos sábados e domingos, costuma pegar a máquina autenticadora e percorrer a área rural e os cinco distritos (...)".

Segundo Lefort 19, a exclusão periódica de milhares de burocratas, longe de ser contrária aos interesses da burocracia, parece atestar sua potência para além da contingência dos indivíduos. Aqueles que trabalham submetidos a cargos burocráticos e ao poder político do Estado se mostram sempre ameaçados de aniquilamento quaisquer que sejam suas posição e autoridade, em razão de sua sujeição ao poder estatal. Analisando a situação de quem ocupa cargo burocrático, Weber 20 afirma que a pessoa padece de uma ambivalência, ou seja, é assalariado, despossuído dos meios de produção, sujeito à maioria das restrições a que estão submetidos os operários - tanto por suas rendas quanto por sua situação de subordinação; contudo, não se identifica, com os trabalhadores manuais.

Com a instalação de novas tecnologias digitais, as coisas na empresa começaram mudar com rapidez. "Com a instalação das novas máquinas, 85\% dos serviços serão automatizados" (Boletim informativo no 8, 1999). A exigência maior era que seus gestores fossem ágeis, abertos às mudanças de curto prazo e tomassem decisões rápidas. Entretanto, esses gestores pareciam, cada vez mais, subordinados às condições impostas pela organização do trabalho. A competitividade era estimulada, o que transformava a reestruturação organizacional numa fonte de ansiedade. "No estágio atual, o rápido come o lento. Não é o grande que come o pequeno. Por isto é preciso transformar a empresa em uma empresa rápida e eficiente" (Boletim informativo no 8, 1999). Uma reestruturação pode causar ansiedade, uma vez que os trabalhadores não sabem que riscos serão compensados e o que os aguarda no futuro profissional. Ela pode tornar-se ainda sinônimo de opressão, principalmente para aqueles que ocupam cargo gerencial, impedindo a construção de metas a longo prazo e a criação de vínculos que exigem tempo, como lealdade, confiança e compromissos institucionais mútuos 21 .

Segundo dados dos questionários sócioeconômicos, esses gestores já trabalhavam na empresa há 21 anos, em média, e estavam há 17 anos no cargo, tendo o primeiro cargo gerencial ocorrido quatro anos após o ingresso. A média de idade era 43 anos. No que se refere à moradia, $77,1 \%$ possuíam casa própria e $22,9 \%$ residiam em imóvel alugado ou financiado. Quanto à escolaridade, apurou-se que 2,8\% tinham o ensino fundamental completo; $2,8 \%$, o ensino médio incompleto; $42,3 \%$, ensino médio; $8,4 \%$, superior incompleto; $42,3 \%$, superior completo e 1,4\% era pós-graduado. Dos 132 gestores que receberam os questionários sócio-econômicos e SRQ-20, apenas 71 responderam a eles, ou seja, 53,8\% de respostas. Quando comparadas as variáveis idade, sexo e tempo no cargo, fornecidas pela empresa, as diferenças não foram consideradas relevantes entre aqueles que responderam aos questionários e os que não o fizeram.

Articulando os dados dos questionários sócio-econômicos e SRQ-20, constatou-se a exis- 
tência de uma associação significativa $(\mathrm{p}<0,05)$ entre gênero e sofrimento, e foi observado que a presença de trabalhadores do sexo feminino com sofrimento $(53,3 \%)$ foi, significativamente, superior à de trabalhadores do sexo masculino $(16,1 \%)$. Os trabalhadores do sexo feminino têm seis vezes mais chance de apresentar sofrimento do que um trabalhador do sexo masculino. As variáveis tempo de empresa, tempo de gerência, idade, situação conjugal, turno de trabalho, propriedade da casa, salário e cargo não influenciaram significativamente $(\mathrm{p}>0,05)$ a presença de sofrimento nessas pessoas. Sendo assim, para cada uma das categorias dessas variáveis, o percentual de presença de sofrimento é semelhante entre os gestores.

A constatação de maior freqüência de sofrimento entre as gestoras pode trazer contribuições para que se compreenda a participação feminina na função gerencial, trazendo para a discussão a relação trabalho, ocupação de cargo de poder e gênero. Entre os que ocupam a alta gerência, apenas $20,1 \%$ são mulheres; na média gerência, elas representam $55,0 \%$; e na gerência de linha, 23,9\%. De forma diferenciada do homem, a inserção feminina no mercado é atravessada por suas responsabilidades domésticas e familiares, obrigando a mulher, muitas vezes, a adaptar o seu cargo a essas funções, o que pode influenciar a maior freqüência de sofrimento. É preciso estudar ainda a especificidade da manifestação do sofrimento feminino no contexto gerencial.

Constatado, através do SRQ-20, que o percentual de sofrimento entre os gestores era de $23,9 \%$, procurou-se dar mais visibilidade a algumas manifestações desse sofrimento e analisá-las. A Tabela 1 mostra os percentuais de sofrimento gerados a partir do SRQ-20 e do grupo focal.

Como pode ser observado na Tabela 1, os resultados tanto do SRQ-20, quanto da representação do sofrimento, obtida do grupo focal, diferem sensivelmente. A utilização das perguntas do questionário como roteiro teve por objetivo instaurar um espaço para discussão, dando voz aos participantes. Na percepção dos pesquisados, o sofrimento é, "no mínimo, o dobro", ou seja, o sofrimento evidenciado pelas respostas do questionário não foi considerado como expressão da realidade. Mesmo seus resultados não sendo epidemiologicamente comparáveis, a utilização desses dois instrumentos mostrou-se útil na medida em que foi capaz de revelar o desafio que constitui a utilização de instrumentos quantitativos nas pesquisas qualitativas.
Ansiedade, tensão e preocupação constituíram as manifestações mais freqüentes do sofrimento $(73,2 \%)$. Sabe-se, há muito, que o nível gerencial é aquele que sofre maior possibilidade de "enxugamento" durante uma reestruturação, por isso a ansiedade pode ser entendida como uma reação relacionada ao perigo, tendo a função de preparar os sistemas psíquicos para enfrentar uma possível perda. Essa manifestação pode estar relacionada ao modo de o gerente experimentar o tempo. Muitas vezes, não existiam condições mínimas para um ordenamento cronológico entre exigência e tempo hábil para execução. Constatou-se que a relação demanda-temporalidade estava permeada por uma impossibilidade lógica. "Eles sempre pedem as coisas para ontem" (Gestor, participante do grupo focal). Na condição pós-moderna o tempo torna-se efêmero, instantâneo, uma sucessão interminável de presentes, em que se pode abolir a noção de passado e, conseqüentemente, de futuro 22 .

Tristeza foi a segunda maior manifestação do sofrimento entre os gestores (43,7\%). A discussão gerada, a partir do grupo focal, sinalizou que a tristeza parece constituir-se numa dimensão com restrito espaço para manifestarse. Foi associada à fraqueza e à depressão, bem como à jornada de trabalho e ao não dormir bem: "A pessoa fica 10, 11 horas no local de trabalho; então, quando chega em casa, não dor$m e$ ", afirma um gestor. A falta de prazer e insatisfação com os resultados também foram associados à tristeza. Transformar este sentimento em depressão, no espaço da fábrica, significa negar um importante elemento da condição humana e abrir possibilidades para a transformação do sofrimento em adoecimento na gestão do trabalho 23. De forma semelhante, o cansar-se com facilidade $(35,2 \%)$ e o sentir-se cansado o tempo todo $(23,9 \%)$ foram associados à fadiga. A substituição da palavra cansaço por fadiga crônica indica o uso de um vocábulo médico que sinaliza a existência de uma morbidade.

A dificuldade de realizar, com satisfação, as atividades da vida diária $(39,0 \%)$ e a perda de interesse pelas coisas $(19,8 \%)$ expressam uma situação de desprazer e mostram como uma vida marcada por atividades sem significação leva ao sofrimento. É possível que se trate de um embotamento afetivo em que o sujeito tornase estranho a si mesmo. Nesses casos, é comum o aparecimento de um distanciamento afetivo claramente percebido pelo cônjuge e pelos filhos, interpretado por estes como "esfriamento" ou desamor 24 . No entanto, é preciso investigar a relação entre esse "embotamento" e o 
processo de reestruturação da empresa, em virtude da incerteza da permanência nos cargos. A ausência do longo prazo no trabalho corrói a motivação, tornando as atividades e a carreira profissional sem atrativos. Onde reina o curto prazo, não há por que e com que se comprometer.

O sofrimento, que aparece através de dores de cabeça $(26,8 \%)$, sono incompleto ou intranqüilo (26,8\%), sensações desagradáveis no estômago $(25,4 \%)$, má digestão $(19,8 \%)$, tremores nas mãos $(9,9 \%)$ e falta de apetite $(5,7 \%)$, é entendido aqui como somatização. Para Dejours 25 o controle limitador e rígido da livre iniciativa é o elemento central que impede o escoamento psíquico de forma adequada nas situações de trabalho, produzindo uma subutilização das vias fantasmáticas, psíquicas e psicossensoriais. A elevada exigência pode estar remetendo seus gestores a uma excessiva contenção de energia no corpo. É possível deduzir que entre eles as vias de escoamento descritas acima parecem insuficientes para possibilitar descarga pulsional. Nesse caso, os gerentes estariam fazendo uso da via mais primitiva, a visceral, para escoar o excesso dessa energia, produzindo somatizações.

Entre os investigados, $11,2 \%$ afirmaram ter algum tipo de dificuldade no exercício gerencial, considerando-o penoso. Para Sato 26, o trabalho é sustentado pela familiaridade, pelo poder e pelo limite subjetivo que possibilitam o exercício do controle sobre o trabalho. A significativa diferença entre aqueles que consideraram o trabalho penoso $(11,2 \%)$ e aqueles que manifestaram sofrimentos como tristeza, insatisfação e cansaço abre uma questão: sob o olhar dos investigados, o sofrimento estaria mais relacionado com a vida fora do trabalho, do que com o trabalho propriamente dito.

O percentual de $73,2 \%$ para tensão e preocupação foi recebido com risos e exclamação. O grupo ficou dividido entre fatores internos e externos à empresa ao se pesquisar a origem de tanta preocupação. Esses sofrimentos foram percebidos como sinais de fraqueza que comprometem a imagem. Os participantes concordam que a empresa e o cargo gerencial não permitem que se demonstre que é fraco e concluem que não há espaço para a manifestação desses sentimentos. Relataram ainda que responderam aos questionários da pesquisa com pressa, uma vez que não tinham tempo para pensar em cada uma das vinte perguntas. $\mathrm{Nu}$ ma situação de grupo, é possível constatar que os sujeitos pensam, agem e sentem de forma diferente quando vistos isoladamente. Eles são capturados por um poder e uma potência que
Tabela 1

Percentuais das manifestações do sofrimento em gestores, obtidos através do SRQ-20 e grupo focal. Belo Horizonte, Minas Gerais, Brasil, 2001.

\begin{tabular}{|c|c|c|}
\hline \multirow[t]{2}{*}{ Questões } & \multicolumn{2}{|c|}{ Presença de manifestações } \\
\hline & SRQ-20 (\%) & Grupo focal (\%) \\
\hline 1. Tem dores de cabeça constantemente? & 26,8 & 55,1 \\
\hline 2. Tem falta de apetite? & 5,6 & 43,6 \\
\hline 3. Dorme mal? & 26,8 & 66,5 \\
\hline 4. Assusta-se com facilidade? & 25,4 & 47,4 \\
\hline 5. Tem tremores nas mãos? & 8,5 & 36,7 \\
\hline 6. Sente-se nervoso, tenso ou preocupado? & 73,2 & 72,4 \\
\hline 7. Tem má digestão? & 19,7 & 56,1 \\
\hline 8. Tem dificuldade de pensar com clareza? & 21,1 & 50,6 \\
\hline 9. Tem-se sentido triste ultimamente? & 43,7 & 61,5 \\
\hline 10. Tem chorado mais que de costume? & 5,6 & 41,6 \\
\hline $\begin{array}{l}\text { 11. Tem dificuldade para realizar com satisfação } \\
\text { suas atividades? }\end{array}$ & 39,4 & 60,5 \\
\hline 12. Tem dificuldade para tomar decisão? & 5,6 & 54,9 \\
\hline 13. Tem dificuldade no serviço? & 12,7 & 53,1 \\
\hline $\begin{array}{l}\text { 14. É incapaz de desempenhar um papel útil } \\
\text { em sua vida? }\end{array}$ & 7,0 & 34,8 \\
\hline 15. Tem perdido o interesse pelas coisas? & 19,7 & 39,0 \\
\hline 16. Você se sente uma pessoa inútil, sem préstimo? & 4,2 & 25,8 \\
\hline 17. Tem tido a idéia de acabar com a vida? & 0,0 & 9,8 \\
\hline 18. Sente-se cansado o tempo todo? & 23,9 & 49,3 \\
\hline 19. Tem sensações desagradáveis no estômago? & 26,8 & 50,5 \\
\hline 20. Você se cansa com facilidade? & 35,2 & 49,7 \\
\hline
\end{tabular}

lhes permitem romper com alguns mecanismos defensivos, tornam-se facilmente sugestionáveis. O grupo é um lugar privilegiado de fomentação de imagens e "lugar de transgressão do proibido", o que pode ter permitido uma maior expressão do sofrimento, no grupo focal 27.

Os últimos momentos de reunião foram marcados pelo fechamento do grupo sobre si mesmo. Ao ser apresentada a porcentagem global de sofrimento entre os gestores, um membro da alta gestão afirmou: "A porcentagem encontrada é compatível com a pesquisa de clima organizacional realizada pela empresa onde o nível de satisfação entre os gestores é superior a 70,0\%”. O grupo praticamente se calou. Quando uma ilusão é ameaçada, os grupos se mostram receptivos a acatar mensagens e líderes que lhes ofereçam uma resposta que traga um pouco mais de certeza e de significado para suas vidas. Se o grupo focal teve um momento catártico, seus próprios membros fizeram, no final, um movimento de proteção, reconstituindo a imagem narcísica ferida para não saírem tão angustiados. Tamponar o sofrimento foi a forma que o grupo encontrou para manter uma 
imagem ideal. Para isso, a realidade organizacional, como lugar de sofrimento, foi suspensa, colocada entre parênteses.

\section{Considerações finais}

Investigar as manifestações do sofrimento em gestores constituiu uma árdua e desafiante tarefa, pois exigiu, em primeiro lugar, circunscrever conceitualmente o sofrimento. Trata-se de um termo impreciso, ora assumido teoricamente na literatura como manifestação de saúde, ora estudado como expressão de doença mental. Trabalhamos com o conceito de sofrimento como uma dimensão contingente à vida e ao trabalho, e não como distúrbio mental menor. Reconhecemos as implicações da imprecisão do conceito na utilização dos diferentes instrumentos de investigação, uma vez que, para o SRQ-20, trata-se de um conjunto de sintomas. Já no grupo focal, trabalhamos com o discurso dos gestores acerca do sofrimento, isto é, consideramos as suas idéias, imagens e percepções.

No grupo focal, o re-conhecimento do sofrimento permitiu ao gerente, naquele momento, posicionar-se como sujeito. A manifestação do sofrimento como farsa ou como tragédia, naquela situação, impulsionou o gestor à tarefa de descobrir-se em seu conflito entre submissão e insubordinação aos determinantes

\section{Resumo}

Estudo transversal conduzido em uma empresa pública, em processo de reestruturação, localizada na região metropolitana de Belo Horizonte, Minas Gerais, Brasil, teve como objetivo evidenciar as manifestações do sofrimento em seus gestores. Utilizaram-se como instrumentos o Self-Report Questionnaire-20 (SRQ-20), questionário sócio-econômico, análise documental e grupo focal. As principais manifestações do sofrimento foram: angústia (73,2\%); tristeza (43,7\%); insatisfação (39,0\%). Das nove variáveis estudadas, apenas o gênero mostrou-se estatisticamente associado $(p<0,05)$ ao sofrimento. As trabalhadoras apresentaram sofrimento significativamente superior ao dos trabalhadores $(\mathrm{OR}=$ 6,0; IC95\%). O grupo focal demonstrou ser um instrumento revelador do sofrimento, enquanto os questionários se mostraram cúmplices das estratégias defensivas, apesar das diferenças conceituais observadas. Concluiu-se que a utilização de distintas abordagens metodológicas em estudos acerca do sofrimento resulta em achados que elas próprias ajudaram a produzir e contribuem para o desenvolvimento do campo da saúde do trabalhador.

Sofrimento Psíquico; Saúde Mental; Saúde Ocupacional organizacionais. Essa técnica, diferente do SRQ20, na qualidade de provoca-ação, tornou-se elemento revela-dor de uma armação marcada pelo imperativo do silêncio estratégico. Os questionários se mostraram cúmplices das estratégias defensivas porque permitiram maior controle por parte dos pesquisados.

Isso implica dizer que os instrumentos de investigação possibilitaram diferentes acontecimentos (no sentido heideggeriano) e estes, por sua vez, produziram diferentes efeitos. Pode-se concluir que essas técnicas resultaram em achados que elas próprias ajudaram a produzir. Nesse sentido, não se fez uma coleta de dados, mas a sua produção por intermédio de determinados meios e visando a certos fins.

O destino do sofrimento dado pelos gestores pode-se constituir em fator de adoecimento ou, ao contrário, de saber fundamental para a construção da saúde. A definição desse destino implica a existência de uma estrutura que possa oferecer um espaço capaz de acolher as manifestações do sofrimento gerencial. A saúde do trabalhador, como campo de conhecimento e de intervenção, poderá se reestruturar para tal. A maneira de trabalhar, sofrer e adoecer durante um processo de reestruturação organizacional exige novas abordagens; exige um lugar para a escuta e para a palavra. A incorporação de estudos acerca do sofrimento na gestão do trabalho pode propiciar enriquecimento ao campo da saúde do trabalhador.

\section{Colaboradores}

L. C. Brant contribuiu na sistematização dos dados, análise dos dados qualitativos, redação geral e interlocução com os pareceristas. E. C. Dias colaborou na sugestão de bibliografia, análise dos dados quantitativos, leitura crítica e desenho do artigo. 


\section{Referências}

1. Uchida S. Temporalidade e subjetividade no trabalho informatizado [Tese de Doutorado]. São Paulo: Instituto de Psicologia, Universidade de São Paulo; 1996.

2. Lopes JC. A voz do dono e o dono da voz: trabalho, saúde e cidadania no cotidiano fabril. São Paulo: Editora Hucitec; 2000.

3. Merlo A. A informática no Brasil. Porto Alegre: Universidade Federal do Rio Grande do Sul; 1999.

4. Palácios M. Sofrimento psíquico e trabalho [Tese de Doutorado]. Rio de Janeiro: Universidade Federal do Rio de Janeiro; 1999.

5. Brant LC. O indivíduo, o sujeito e a epidemiologia. Ciênc Saúde Coletiva 2001; 6:221-31.

6. Gramsci A. A concepção dialética da história. Rio de Janeiro: Civilização Brasileira; 1984.

7. Dias EC. A atenção à saúde dos trabalhadores no setor saúde (SUS), no Brasil [Tese de Doutorado]. Campinas: Faculdade de Ciências Médicas, Universidade Estadual de Campinas; 1994.

8. Hegel G. A fenomenologia do espírito. 2a Ed. Petrópolis: Editora Vozes; 1999.

9. Freud S. Além do princípio do prazer. In: Edição standard brasileira das obras psicológicas completas. vol. XVIII. Rio de Janeiro: Imago; 1920.

10. Rorty R. Ensaios sobre Heidegger e outros. Rio de Janeiro: Relume-Dumará; 1999.

11. Bardin L. Análise de conteúdo. Lisboa: Edições $70 ; 1977$.

12. Mari J, Williams P. A validity study of a psychiatric screening questionnaire (SRQ-20) in primary care in the city of São Paulo. Br J Psychiatry 1986; 148: 23-6.

13. Krueger, R. Focus group: a practical guide for applied research. 2nd Ed. Thousand Oaks: Sage; 1994.

14. Triviños A. Introdução à pesquisa em ciências sociais: a pesquisa qualitativa em educação. São Paulo: Editora Atlas; 1987.

15. Minayo MC. O desafio do conhecimento: pesquisa qualitativa em saúde. 4a Ed. São Paulo: Editora Hucitec/ABRASCO; 1996.
16. Oliveira PT. O sofrimento psíquico e o trabalho hospitalar: um estudo de caso realizado em um hospital no Pará [Dissertação de Mestrado]. Rio de Janeiro: Escola Nacional de Saúde Pública, Fundação Oswaldo Cruz; 1998.

17. Palácios M. Trabalho hospitalar e saúde mental: o caso de um hospital geral e público no Município do Rio de Janeiro [Dissertação de Mestrado]. Rio de Janeiro: Centro Biomédico, Universidade do Estado do Rio de Janeiro; 1993.

18. Marx K, Engels F. Manifesto do partido comunista. Petrópolis: Editora Vozes; 1990.

19. Lefort C. A invenção democrática. São Paulo: Editora Brasiliense; 1983.

20. Weber M. Os fundamentos da organização do trabalho burocrático. In: Campos E, organizador. Sociologia da burocracia. Rio de Janeiro: Jorge Zahar Editor; 1966. p. 16-27.

21. Sennett R. A corrosão do caráter. Rio de Janeiro: Record; 2000.

22. Harvey D. Condição pós-moderna. São Paulo: Edições Loyola; 1993.

23. Brant L, Minayo-Gomez C. A transformação do sofrimento em adoecimento: do nascimento da clínica à psicodinâmica do trabalho. Ciênc Saúde Coletiva 2004; 9:213-23.

24. Seligman-Silva E. Psicopatologia e psicodinâmica no trabalho. In: Mendes R, organizador. Patologia do trabalho. Belo Horizonte: Editora Atheneu; 1995. p. 287-310.

25. Dejours C. A loucura do trabalho. 5a Ed. São Paulo: Editora Cortez; 1992.

26. Sato L. A abordagem psicossocial do trabalho penoso [Dissertação de Mestrado]. São Paulo: Pontifícia Universidade Católica de São Paulo; 1991.

27. Anzieu D. El grupo y el inconsciente. Madrid: Biblioteca Nueva; 1978.

Apresentado em 05/Jun/2003

Versão final reapresentada em 10/Nov/2003

Aprovado em 10/Dez/2003 